\title{
Thiosemicarbazones Functioning as Zinc Metallochaperones to Reactivate Mutant p53 $\mathrm{g}$
}

\author{
Xin Yu, Adam Blanden, Ashley T. Tsang, Saif Zaman, Yue Liu, John Gilleran, \\ Anthony F. Bencivenga, S. David Kimball, Stewart N. Loh, and Darren R. Carpizo
}

Rutgers Cancer Institute of New Jersey (X.Y., A.T.T., S.Z., Y.L., D.R.C.), Department of Surgery, Rutgers Robert Wood Johnson Medical School (X.Y., A.T.T, Y.L., D.R.C.), Rutgers Translational Sciences, Department of Chemistry and Chemical Biology (S.D.K.), Department of Medicinal Chemistry, Rutgers Ernest Mario School of Pharmacy (J.G., A.F.B., S.D.K.), Rutgers University, New Brunswick, New Jersey; Department of Biochemistry and Molecular Biology, State University of New York (SUNY) Upstate Medical University, Syracuse, New York (A.B., S.N.L.); and Mount Sinai St. Luke's Roosevelt General Surgery Residency Program, New York, New York (A.T.T.)

Received November 4, 2016; accepted March 16, 2017

\section{ABSTRACT}

Small-molecule restoration of wild-type structure and function to mutant p53 (so-called mutant reactivation) is a highly soughtafter goal in cancer drug development. We previously discovered that small-molecule zinc chelators called zinc metallochaperones (ZMCs) reactivate mutant p53 by restoring zinc binding to zincdeficient p53 mutants. The lead compound identified from the NCl-60 human tumor cell lines screen, NSC319726 (ZMC1), belongs to the thiosemicarbazone (TSC) class of metal ion chelators that bind iron, copper, magnesium, zinc, and other transition metals. Here, we have investigated the other TSCs, NSC319725 and NSC328784, identified in the same screen, as well as the more well studied TSC, 3-AP (Triapine), to determine whether they function as ZMCs. We measured the zinc $K_{\mathrm{d}}$ zinc ionophore activity, ability to restore zinc to purified p53 DNA binding domain (DBD), and ability to restore site-specific DNA binding to purified $\mathrm{R} 175 \mathrm{H}-\mathrm{DBD}$ in vitro. We tested all four TSCs in a number of cell-based assays to examine mutant p53 reactivation and the generation of reactive oxygen species (ROS). We found that NSC319725 and NSC328784 behave similarly to ZMC1 in both biophysical and cell-based assays and are heretofore named ZMC2 (NSC319725) and ZMC3 (NSC328784). 3-AP generates a ROS signal similar to ZMC1-3, but it fails to function as a ZMC both in vitro and in cells and ultimately does not reactivate $\mathrm{p} 53$. These findings indicate that not all TSCs function as ZMCs, and much of their activity can be predicted by their affinity for zinc.

\section{Introduction}

TP53 is the most commonly mutated gene in human cancer, and it plays an essential role as a tumor suppressor (Levine and Oren, 2009; Freed-Pastor and Prives, 2012; Bieging et al., 2014). Most mutations $(>70 \%)$ are missense and generate a defective protein that is generally found at high levels in cancer cells as a result of the loss of MDM2-mediated negative feedback (Haupt et al., 1997). Restoring wild-type (WT) p53 function by genetic means in mouse models of cancer triggers potent anticancer activity (Ventura et al., 2007; Xue et al., 2007). Thus, reactivation of WT structure/function of mutant p53 using small molecules has been an area of intense investigation in anticancer drug development.

This work was supported by the National Institutes of Health [Grants R01CA200800, K08CA172676], Sidney Kimmel Foundation for Cancer, and the Breast Cancer Research Foundation and the NIH [F30GM113299].

X.Y. and A.B. contributed equally to this work.

https://doi.org/10.1124/mol.116.107409.

S This article has supplemental material available at mol.pharm aspetjournals.org.
The p53 protein requires the binding of a single zinc ion for proper folding. Evidence now has shown that manipulating zinc concentrations can change the structure and function of WT p53, indicating that the structure is malleable (Hainaut and Milner, 1993; Méplan et al., 2000; Butler and Loh, 2003). This concept also applies to certain mutant p53s in which the mutated amino acid impairs the protein's ability to coordinate zinc and causes misfolding. The three major classes of mutant p53 proteins are destabilizing, DNA-contact, and zincbinding, each of which impairs the protein for different reasons and presents its own unique challenges for targeted drug development. The zinc-binding class is best exemplified by the most common p53 mutant found in cancer, $\mathrm{p} 53-\mathrm{R} 175 \mathrm{H}$.

Using an in silico screen of the NCI-60 human tumor cell lines to screen the anticancer drug database, we previously identified three small molecules (NSC319725, NSC319726, NSC328784) that belong to the thiosemicarbazone (TSC) family of metal ion chelators with high activity in cell lines with mutant p53 (Yu et al., 2012a). We went on to demonstrate that NSC319726 (ZMC1) kills cancer cells by restoring the WT structure and function of $\mathrm{p} 53-\mathrm{R} 175 \mathrm{H}$ both in vitro and in vivo

ABBREVIATIONS: 3-AP, Triapine; apo, zinc-free; CF, carboxyfluorescein; DBD, DNA binding domain; DOPC, 1,2-dioleoyl-sn-glycero-3-phosphocholine; EMSA, electrophoretic mobility shift assay; PAR, 4-(2-pyridylazo)resorcinol; ROS, reactive oxygen species; RR, ribonucleotide reductase; RZ-3, RhodZin-3; TCEP, tris(2-carboxyethyl)phosphine hydrochloride; TSC, thiosemicarbazone; WT, wild-type; ZMC, zinc metallochaperone. 
(Yu et al., 2012a). We elucidated the ZMC1 mechanism by finding that: 1) ZMC1 is a zinc metallochaperone (ZMC) that delivers zinc to $\mathrm{p} 53-\mathrm{R} 175 \mathrm{H}$ by functioning as a zinc ionophore, thus allowing the mutant to fold properly; and 2) ZMC1 boosts intracellular reactive oxygen species (ROS), which transactivates the newly conformed mutant through amino-terminal post-translational modifications (Yu et al., 2014; Blanden et al., 2015b). We found that other zinc chelators with a similar affinity $\left(K_{\mathrm{d}}\right)$ for zinc can function as ZMCs to restore WT conformation to p53-R175H (Hainaut and Milner, 1993; Butler and Loh, 2003).

The model for ZMC restoration of WT p53 structure posits two types of zinc ligation sites on p53: native $\left(K_{\mathrm{d} 1}\right)$ and nonnative $\left(K_{\mathrm{d} 2}\right)$ (Yu et al., 2014). We experimentally determined the $K_{\mathrm{d} 1}$ of the R175H DBD to be on the order of $10^{-9} \mathrm{M}$, which is 10 - to 1000 -fold greaterer than physiologic zinc concentrations $\left(10^{-12}-10^{-10} \mathrm{M}\right)$, indicating that $\mathrm{R} 175 \mathrm{H}$ is likely in the apo (zinc-free) form in the cell (Bozym et al., 2006). Raising intracellular zinc above $10^{-9} \mathrm{M}$ can, in principle, restore WT conformation to $\mathrm{R} 175 \mathrm{H}$, but if levels rise above the dissociation constant of the non-native ligation sites $\left(K_{\mathrm{d} 2} \sim 10^{-6}\right)$, the protein will again misfold. ZMCs like ZMC1 restore WT structure to mutant p53 by raising intracellular zinc concentrations to greater than the $K_{\mathrm{d} 1}$ of the $\mathrm{p} 53-\mathrm{R} 175 \mathrm{H}$ while at the same time functioning as zinc buffers to prevent zinc induced misfolding.

TSCs have an affinity for divalent metal ions, such as $\mathrm{Fe}^{2+}$, $\mathrm{Zn}^{2+}, \mathrm{Cu}^{2+}$, and $\mathrm{Mn}^{2+}$, and have been investigated as anticancer drugs, the most notable being 3 -aminopyridine-2carboxaldehyde (3-AP or Triapine) (Finch et al., 2000). 3-AP is currently in phase 2 clinical trials for aggressive myeloproliferative neoplasms, advanced-stage cervical and vaginal cancers, advanced renal carcinoma, and advanced non-small cell lung cancer (Yu et al., 2012b; Kunos et al., 2013; Zeidner et al., 2014). The mechanism of action of TSCs has been attributed to the inhibition of the iron-dependent enzyme ribonucleotide reductase, as well as TSC-iron complexes that contribute to cell death by facilitating Fenton chemistry and increasing oxidative stress (Richardson et al., 2006; Shao et al., 2006). These features have plagued the development of these drugs owing to toxicities related to methemoglobinemia and bone marrow suppression, among others (Murren et al., 2003; Ma et al., 2008). Given that NSC319725 and NSC328784, as well as 3-AP, all belong to the same chemical class, we sought to investigate whether these compounds could function as zinc metallochaperones to reactive mutant p53 in addition to any other reported activities.

\section{Materials and Methods}

Chemicals. NSC319726 (ZMC1), NSC319725 (hereafter ZMC2) and NSC328784 (hereafter ZMC3) were synthesized by the Rutgers Translational Sciences group. 3-AP was purchased from SigmaAldrich (St. Louis, MO). 1,2-dioleoyl-sn-glycero-3-phosphocholine (DOPC) was purchased from Avanti Polar Lipids (Alabaster, AL). RhodZin-3 (RZ-3) was purchased from Life Technologies Corporation (Norwalk, CT). MTS reagent was purchased from Promega (Madison, WI). All other chemicals were purchased from Sigma-Aldrich or as otherwise indicated.

Protein Preparation. The p53 (94-312) DNA binding domains (DBD) were expressed and purified as described previously (Yu et al., 2014). Apo proteins were generated as described previously (Butler and Loh, 2003). All experiments were performed in $50 \mathrm{mM}$ Tris $(\mathrm{pH}$
7.2), $0.1 \mathrm{M} \mathrm{NaCl}$, and $1 \mathrm{mM}$ tris(2-carboxyethyl)phosphine hydrochloride (TCEP) unless otherwise noted.

Spectroscopic Measurements. Absorbance experiments were performed in a Varian Cary-100 UV-Visible spectrophotometer equipped with a thermostatted cuvette holder, and fluorescence experiments were performed on a Fluoromax-4 spectrofluorimeter equipped with thermostatted cuvette holder (HORIBO Jobin-Yvon Inc, Edison, NJ). Fluorescence measurements were recorded in a $1 \mathrm{~cm} \times 1$-cm quartz cuvette with excitation and emission slits of $3 \mathrm{~nm}$ and $4 \mathrm{~nm}$, respectively. All experiments were conducted at $10^{\circ} \mathrm{C}$ unless otherwise noted.

RZ-3-Zn ${ }^{2+}$ Competition Assay. RZ-3 at $100 \mathrm{nM}$ and $\mathrm{ZnCl}_{2}$ at $50 \mathrm{nM}$ were incubated with the indicated concentration of TSC in buffer with $4 \% \mathrm{v} / \mathrm{v}$ dimethylsulfoxide at room temperature and allowed to equilibrate for $>1$ hour. RZ-3 fluorescence was then measured and the $\mathrm{IC}_{50}$ determined by fitting to a sigmoid curve on a semi-log axis. This $\mathrm{IC}_{50}$ value was then divided by 2 to account for the known 2:1 binding stoichiometry of these compounds, and the apparent $K_{\mathrm{d}}$ was calculated according to the Munson-Robard exact solution to the Cheng-Prussof equation (eq. 1):

$$
K_{i}=\frac{I C 50}{1+\frac{L_{T}\left(y_{0}+2\right)}{2 K_{d}\left(y_{0}+1\right)}+y_{0}}-K_{d} \frac{y_{0}}{y_{0}+2},
$$

where $K_{\mathrm{i}}$ is the apparent $K_{\mathrm{d}}$ of the TSC, $L_{\mathrm{T}}$ is the total concentration of RZ-3 $(100 \mathrm{nM}), K_{\mathrm{d}}$ is the dissociation constant of RZ-3 for $\mathrm{Zn}^{2+}(65 \mathrm{nM}$ per manufacturer), and $y_{0}$ is the ratio of bound RZ-3 to free RZ-3 in the absence of TSC ( $26.5 \mathrm{nM} / 73.5 \mathrm{nM}$ under these conditions).

Arrested Refolding. Arrested refolding experiments were performed as described previously with minor modifications (Butler and Loh, 2007). DBD ( $25 \mu \mathrm{M})$ was denatured in buffer containing $5 \mathrm{M}$ urea and then rapidly diluted 50 -fold into urea-free buffer with or without $2.5 \mu \mathrm{M} \mathrm{ZnCl}_{2}$ to final concentrations of $0.5 \mu \mathrm{M} \mathrm{DBD}$ and $0.1 \mathrm{M}$ urea with continuous magnetic stirring. Intrinsic tryptophan fluorescence was monitored at the absorbance isosbestic point between the $\mathrm{Zn}^{2+}$. bound and $\mathrm{Zn}^{2+}$-free forms of the drug to minimize changes in innerfilter effect throughout the experiment (ZMC2 $338 \mathrm{~nm}$, ZMC3 $355 \mathrm{~nm}, 3-\mathrm{AP} 376 \mathrm{~nm}$, excitation $280 \mathrm{~nm}$ ). For $\mathrm{ZnCl}_{2}$-containing samples, after $\sim 90$ seconds of stalled folding, the indicated concentration of EDTA, compounds, or dimethylsulfoxide vehicle was added and folding monitored as before. Kinetic traces were corrected for innerfilter effect empirically.

$\mathbf{Z n}^{2+}$ Content Measurement. DBD samples were desalted using

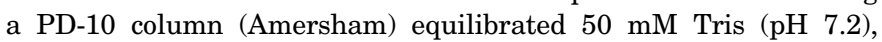
$150 \mathrm{mM} \mathrm{NaCl}$, and $1 \mathrm{mM}$ TCEP. Samples $(1-10 \mu \mathrm{M})$ were then unfolded in $6 \mathrm{M} \mathrm{Gdn-HCl}$ and reacted with $1 \mathrm{mM}$ N-ethylmaleimide for 20 minutes at room temperature to ensure complete release of all bound $\mathrm{Zn}^{2+}$. The reaction was quenched with $10 \mathrm{mM} \beta-\mathrm{ME}$ for $10 \mathrm{~m}$, and $\mathrm{Zn}^{2+}$ concentration measured by adding $150 \mu \mathrm{M} 4$-(2-pyridylazo)resorcinol (PAR) and measuring the absorbance blanked against PAR in buffer using $\epsilon_{500}=5.0 \times 10^{4} \mathrm{M}^{-1} \mathrm{~cm}^{-1}$ for the $\mathrm{PAR}_{2}$-zinc complex in buffer containing $6 \mathrm{M} \mathrm{Gdn-HCl}$ as determined by our laboratory. Measured $\mathrm{Zn}^{2+}$ concentration was divided by protein concentration to determine $\mathrm{Zn}^{2+}$ content of the protein.

Remetallation. After apoization, DBD $(15-30 \mu \mathrm{M})$ was incubated with a mixture of $60 \mu \mathrm{M} \mathrm{ZnCl}_{2}, 180 \mu \mathrm{M}$ compound for 20 minutes on ice. Samples were then desalted, and $\mathrm{Zn}^{2+}$ content assayed as described. For $\mathrm{Zn}^{2+}$ remetallation experiments, data for WT and R175H DBD were analyzed separately via one-way analysis of variance, and then all pairwise comparisons were analyzed with the Holm-Sidak method for multiple comparisons with an overall significance level of $P<0.05$ in SigmaPlot 13.0.

Ionophore Assay. DOPC liposomes $(100 \mathrm{~nm}$ ) were prepared by film rehydration and extrusion as described previously (Blanden et al., 2015b). RZ-3 and carboxyfluorescein (CF) were encapsulated at $10 \mu \mathrm{M}$ and $100 \mathrm{mM}$, respectively. Liposome solutions were diluted to $\mathrm{OD}_{600}<$ 0.02 before use, and measurements were taken in a $5 \times 5$-mm quartz cuvette at room temperature. Excitation and emission wavelengths were 550/572 $\mathrm{nm}$ for RZ-3 and 492/512 $\mathrm{nm}$ for CF. 
Cell Lines and Culture Conditions. TOV112D and H1299 were cultured in DMEM with 10\% fetal bovine serum. H460, SKBR3, and HOP92 were cultured in RPMI with $10 \%$ fetal bovine serum.

Cell Growth Inhibition Assay. MTS assay was performed according to the manufacturer's instructions (Promega). In brief, 5000 cells/well were cultured in 96 -well plates to reach the $50 \%$ confluence on the 2 nd day when treated with serial dilutions of the compounds. Growth was measured by MTS reagent and Victor Plate reader instrument (PerkinElmer, Boston, MA) after incubation for 3 days.

Transfection of p53 siRNA. The siRNA transfection is done with LipofectAMINE RNAiMAX (Invitrogen, Carlsbad, CA) according to the manufacturer's instructions. The p53 siRNA was from SMARTpool (Thermo Fisher Scientific/Dharmacon, Lafayette, CO). The cells after 24-hour transfection were reseeded to 96-well plates for treatment of the compounds, and the cell growth inhibition was measured by CellTiter-Glo (Promega) according to the manufacturer's instructions. Statistical significance of the data, obtained from two independent experiments, each with triplicates, was calculated using Student's $t$ test.

Colony Formation Assays. For long-term viability, 1000 cells/ well on six-well plates were treated with the compounds at various concentrations for 6 hours; then the cells were cultured with drug-free complete medium for 10 days with fresh medium without interference. Cells were fixed with $10 \%$ formalin and stained with $0.05 \%$ crystal violet at the end of 10-day period of cell culture (Franken et al., 2006). Statistical significance of the data, obtained from three independent experiments, each in triplicate, was calculated using Student's $t$ test.

Immunofluorescent Staining. Cells were grown on coverslips, followed by various treatments. The coverslips were fixed with $4 \%$ paraformaldehyde for 10 minutes and then permeabilized with $0.5 \%$ Triton-X100 for 5 minutes. Conformation of the mutant and WT p53 proteins were recognized specifically by the antibodies PAB1620 (1:50, recognizing WT conformation) and PAB240 (1:400, recognizing misfolded/unfolded conformation) stained overnight, respectively. The secondary antibody, goat anti-mouse IgG, was incubated for 40 minutes. PAB1620 and PAB240 were purchased from EMD Chemicals Inc (Gibbstown, NJ).

RNA Extraction and Quantitative Reverse-Transcription Polymerase Chain Reaction. RNA was extracted from the cells using RNeasy kit (Qiagen, Valencia, CA), and the gene expression level was measured by quantitative reverse-transcription polymerase chain reaction using TaqMan gene expression assays (Life Technologies/Applied BioSystems). The gene expression level was normalized with $\beta$-actin, and the average was presented with S.D. Statistical significance of the data was calculated by Student's $t$ test.

Western Blot. The cell lysates were run on SDS-PAGE and transferred onto polyvinylidene fluoride membranes. Detection of the protein level was performed according to the manufacturer's instructions (Western Lightning Plus-ECL, PerkinElmer). The p21 antibody was purchased from EMD Chemicals. The actin antibody was purchased from Santa Cruz Biotechnology (Dallas, TX).

8-Oxy-dG Staining. We purchased 8-oxy-dG (clone 2E2) antibody from Trevigen (Gaithersburg, MD). Immunocytochemistry staining was performed according to the manufacturer's instructions. Staining was quantified by density/brightness using ImageJ Software. Statistical significance of the data was calculated by Student's $t$ test.

Electrophoretic Mobility Shift Assay. Purified p53 apoDBD $(\mathrm{R} 175 \mathrm{H})$ was used in the indicated reactions. DNA was 44-bp p53 recognition sequence ( $\mathrm{p} 53 \mathrm{RE})$ in the promoter sequence of $\mathrm{p} 21$ gene (Lokshin et al., 2007), 5' F-AGCTAGTAGAGCGAACATGTCCCAACATGTTGGCGTGCTGCAGC, 5' R-GCTGCAGCACGCCAACATGTTGGGACATGTTCGCTCTACTAGCT. DNA was labeled with biotin with a DNA 3 '-end biotinylation kit (ThermoFisher Scientific/ Pierce). The reaction mixture was incubated at $4^{\circ} \mathrm{C}$ for 10 minutes before the addition of biotin-labeled probes. Binding buffer was described previously (Lokshin et al., 2007). DNA binding reactions were carried out at $4^{\circ} \mathrm{C}$ for 20 minutes, and the resulting DNA-protein complexes were separated on a $6 \%$ polyacrylamide gel (made with $30 \%$ acrylamide/bis solution (37.5:1; Bio-Rad, Hercules, CA)) in $0.5 \times$ Trisborate (without EDTA) running in $0.5 \times$ Tris-borate (without EDTA) buffer. Complexes were visualized by LightShift Chemiluminescent EMSA kit (Thermo Fisher Scientific/Pierce).

Statistical Methods. For $\mathrm{Zn}^{2+}$ remetallation experiments, data for WT and R175H DBD were analyzed separately via one-way analysis of variance, and then all pairwise comparisons were analyzed with the Holm-Sidak method for multiple comparisons with an overall significance level of $P<0.05$ in SigmaPlot 13.0. The other data were analyzed by Student's $t$ test with an overall significance level of $P<$ $0.05 ; * P<0.05$; ** $P<0.01$; *** $P<0.001$.

\section{Results}

ZMC2 and ZMC3 Exhibit Zinc Metallochaperone Properties, whereas 3-AP Does Not. ZMC1, ZMC2, ZMC3, and 3-AP are heteroaromatic substituted TSCs and share the characteristic N-N-S(Se) backbone of a general TSC and selenosemicarbazone. The chemical structures are depicted in Fig. 1A.

To both chelate zinc in the extracellular space and donate zinc to mutant p53, ZMCs must bind zinc with an affinity similar to that of the native site on DBD. We have previously determined the zinc $K_{\mathrm{d}}$ of ZMC1 to be $\sim 30 \mathrm{nM}$ (Yu et al., 2014). To determine whether ZMC2, ZMC3, and 3-AP bind $\mathrm{Zn}^{2+}$ in the affinity range of a ZMC, which according to our current understanding of the ZMC mechanism is $\sim 10^{-9}-10^{-6} \mathrm{M}$ (Yu et al., 2014; Blanden et al., 2015a,b), we measured their apparent $\mathrm{Zn}^{2+} K_{\mathrm{d}}$ by competition with fluorescent $\mathrm{Zn}^{2+}$ chelator RZ-3 (Fig. 1B). ZMC2 and ZMC3 both bound with a $K_{\mathrm{d}}$ in the range required for $\mathrm{R} 175 \mathrm{H}$ reactivation $(27.4 \pm 16.2$ $\mathrm{nM}$ and $81 \pm 34.2 \mathrm{nM}$, respectively). 3-AP did not bind $\mathrm{Zn}^{2+}$ under the assay conditions, which corresponds to $K_{\mathrm{d}}>1 \mu \mathrm{M}$ and is above the upper limit required by the ZMC model.

To evaluate the ability of $\mathrm{ZMC} 2, \mathrm{ZMC} 3$, and 3-AP to remetallate apoDBD, as is required for $\mathrm{Zn}^{2+}$-deficient p53 reactivation, we incubated WT and $\mathrm{R} 175 \mathrm{H}$ apoDBD with a $3: 1$ mixture of TSC: $\mathrm{ZnCl}_{2}$ and assayed the resultant $\mathrm{Zn}^{2+}$ content of the proteins using colorimetric $\mathrm{Zn}^{2+}$ indicator PAR (Fig. 1C). All three compounds were able to restore the $\mathrm{Zn}^{2+}$ content of the apo proteins, with $\mathrm{ZMC} 3$ and 3-AP restoring more $\mathrm{Zn}^{2+}$ than ZMC2. When we assayed the foldedness of the remetallated proteins by intrinsic tryptophan fluorescence, leveraging the known property of DBD to increase in fluorescence when it misfolds (Yu et al., 2014), we found that the proteins remetallated with $\mathrm{ZMC} 2$ and $\mathrm{ZMC} 3$ were native and the proteins remetallated with 3-AP were misfolded (Fig. 1D).

We then evaluated the ability of ZMC2, ZMC3, and 3-AP to rescue the folding of DBDs that had previously been misfolded by excess $\mathrm{Zn}^{2+}$, a known property of synthetic ZMCs (Fig. 1, E-G; Supplemental Fig. 1) (Butler and Loh, 2007; Yu et al., 2014). Briefly, WT and R175H DBD were unfolded in urea and then refolded by rapid dilution in the presence or absence of excess $\mathrm{ZnCl}_{2}$. In the presence of excess $\mathrm{ZnCl}_{2}$, the proteins become trapped in the highly fluorescent misfolded state. After $\sim 60$ seconds, a 4-fold molar excess of TSC (two binding equivalents) was added and refolding monitored by fluorescence as DBD converted from the highly fluorescent misfolded state to the weakly fluorescent native state. Both ZMC2 and ZMC3 efficiently rescued the folding of R175H and WT DBD with equal or superior efficiency relative to the known $\mathrm{Zn}^{2+}$ chelator EDTA, whereas 3-AP had no effect on either. 
A

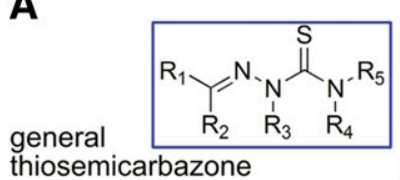<smiles>C/C(=N\NC(=S)N1CCC1)c1ccccn1</smiles>
$\mathrm{ZMC1}-\mathrm{CH}_{3} \mathrm{H}$<smiles>C/C(=N\NC(=S)N(C)C)c1ccccn1</smiles><smiles>CC(=NNC(=[Se])N1CCN(c2ccccn2)CC1)c1ccccn1</smiles>

H ZMC3<smiles>NC(=S)N/N=C/c1ncccc1N</smiles>

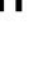

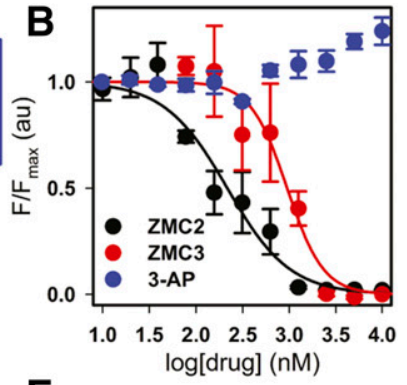
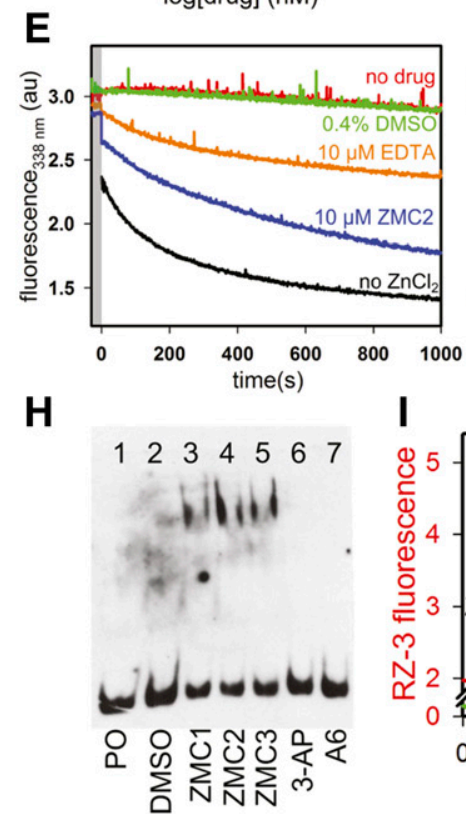

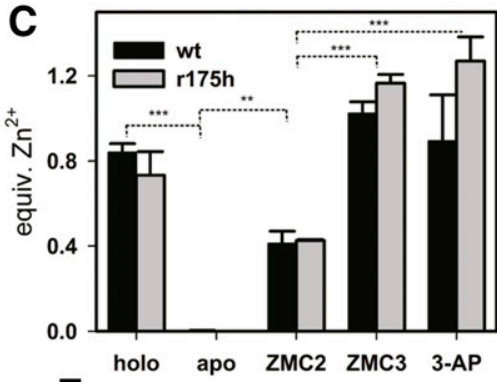

$\mathbf{F}$
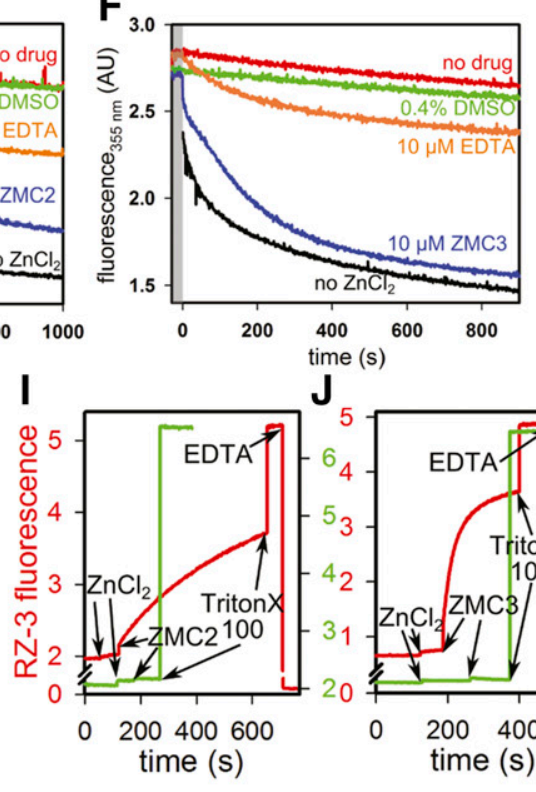
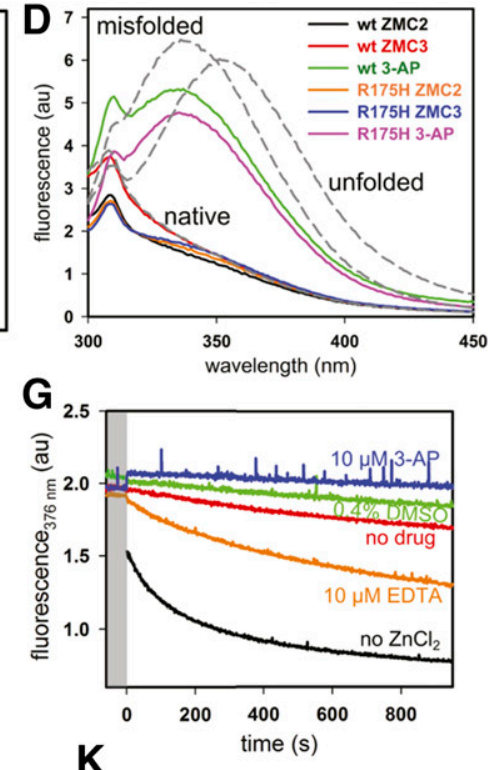

J

Fig. 1. In vitro evaluation of TSCs as ZMCs. (A) Scheme of the four TSCs: ZMC1, ZMC2, ZMC3, and 3-AP. (B) Competition assay between TSCs and RZ-3. Apparent $K_{\mathrm{d}}$ values were calculated according to eq. $1 . K_{\mathrm{d}}=27.4 \pm 16.2(\mathrm{ZMC} 2), 81.0 \pm 34.2(\mathrm{ZMC})$, and $>1 \mu \mathrm{M}(3-\mathrm{AP})$. [RZ-3] $=100 \mathrm{nM}$, $\left[\mathrm{ZnCl}{ }_{2}\right]=50 \mathrm{nM}$. Error bars \pm S.D . $(n \geq 3)$. (C) DBD remetallation assay. R175H and WT DBDs $(\sim 20 \mu \mathrm{M})$ were apoized and then incubated with a mixture of $180 \mu \mathrm{M}$ TSC and $60 \mu \mathrm{M} \mathrm{ZnCl}_{2}$. DBD Zn ${ }^{2+}$ content was then measured by PAR assay. Error bars \pm S.D. $(n \geq 3)$. $P$ values from one-way analysis of variance using the Hilm-Sidak method for multiple comparisons. All three compounds can release metal back to apoized DBD. $* P<0.05 ; * * P<0.01 ; * * P<0.001$. (D) Fluorescence spectra of proteins remetallated in (C). Gray dotted lines show basis spectra of WT DBD either in buffer alone (native), with 8 M urea (unfolded), or with $10 \mu \mathrm{M} \mathrm{ZnCl}_{2}$ (misfolded). [DBD] = $0.5 \mu \mathrm{M}$. Proteins remetallated with ZMC2 and ZMC3 are mostly native and with 3-AP are mostly misfolded. (E-G) $\mathrm{Zn}^{2+}$-arrested-refolding assays for ZMC2 (E), ZMC3 (F), and 3-AP (G). R175H DBD was unfolded in $5 \mathrm{M}$ urea, then diluted into buffer to the final concentrations of $0.5 \mu \mathrm{M} \mathrm{DBD}, 0.1 \mathrm{M}$ urea, and $2.5 \mu \mathrm{M} \mathrm{ZnCl}_{2}$. Treatments were added at time $=0$. Disappearance of the misfolded fluorescence peak was monitored at the isosbestic point between the TSC and TSC- $\mathrm{Zn}^{2+}$ complex. Traces shown were corrected empirically for inner filter effect. Gray boxes represent the arrested phase of the experiment. ZMC2 and ZMC3 are able to rescue the folding of R175H DBD, but 3-AP is not. (H) Electrophoretic mobility shift assay (EMSA) using R175H DBD. apoDBD was incubated with with $\mathrm{ZnCl}_{2}(10 \mu \mathrm{M})$ and either ZMC1, ZMC2, ZMC3, A6, or 3-AP (20 $\left.\mu \mathrm{M}\right)$ in $\mathrm{TB}(\mathrm{noE})$ buffer running on 6\% native PAGE. Lanes 3-7 contained the combination of drug $(20 \mu \mathrm{M})$ and $\mathrm{ZnCl}_{2}(10 \mu \mathrm{M})$. Only the ZMC1, ZMC2, and ZMC3 restored site-specific DNA binding to the R175H DBD (lanes 3-5). A6 is used as a negative control. (I-K) $\mathrm{Zn}^{2+}$-import kinetics and liposome leakage assay measured by DOPC-encapsulated RZ-3 (red) and CF (green) fluorescence, respectively, for ZMC2 (H), ZMC3 (I), and 3-AP (J). Treatments were added at the arrows. RZ-3 was encapsulated at $10 \mu \mathrm{M}$ and CF at $100 \mathrm{mM}$. Concentrations shown are $10 \mu \mathrm{M} \mathrm{ZnCl}_{2}, 1 \mu \mathrm{M}$ TSC, $1 \%$ TritonX-100, and $100 \mu \mathrm{M}$ EDTA. ZMC2 and ZMC3 have $\mathrm{Zn}^{2+}$ ionophore activity, but 3-AP does not. None of the treatments disrupted the liposomes nonspecifically. Data represented an average \pm S.D. of three experiments performed in triplicate (B and C), and representative data are shown from three experiments (D-K).

To confirm that the conformation induced by ZMC2 and ZMC3 was WT, we turned to the electrophoretic mobility shift assays (EMSA) to evaluate whether the TSCs and zinc could restore site-specific binding to apo R175H DBD using a DNA oligonucleotide bearing the p21 recognition sequence (Fig. $1 \mathrm{H})$. Previously, we demonstrated that ZMC1 only in the presence of zinc could restore site-specific DNA binding to the R175H DBD (Yu et al., 2014). Using the EMSA, we evaluated $\mathrm{ZMC}$, ZMC3, and 3-AP using ZMC1 as a positive control and $\mathrm{A} 6$ as a negative control. $\mathrm{A} 6$ is an analog of $\mathrm{ZMC} 1$ whose $\mathrm{ZMC}$ activity has been abolished by $\sim 30$-fold decrease in zinc binding (Yu et al., 2014). The combination of $10 \mu \mathrm{M} \mathrm{ZnCl}_{2}$ and $20 \mu \mathrm{M}$ ZMC1 (lane 3), ZMC2 (lane 4), and ZMC3 (lane 5) restored DNA binding to $\mathrm{R} 175 \mathrm{H}$ apoDBD, but not with 3-AP (Lane 6), A6 (lane 7) or apoDBD alone (lane 2).
We then evaluated the compounds for ionophore activity as required by the ZMC mechanism. Briefly, we encapsulated fluorescent $\mathrm{Zn}^{2+}$ indicator RZ-3 in DOPC liposomes and monitored $\mathrm{Zn}^{2+}$ transport into the liposomes using the increase RZ-3 fluorescence upon $\mathrm{Zn}^{2+}$ binding, as previously described (Blanden et al., 2015b). Both ZMC2 and ZMC3 caused a significant increase in the rate of $\mathrm{Zn}^{2+}$ transport into the liposomes; 3-AP caused no detectible increase. The increase in RZ-3 fluorescence was completely reversible upon detergent lysis and the addition of excess EDTA, indicating that the increase was caused exclusively by metal binding. We also performed a nonspecific leakage control using selfquenching fluorophore $\mathrm{CF}$ and found no nonspecific leakage from the liposomes for any of the compounds (Fig. 1, I-K) (Blanden et al., 2015b). Taken together, these data indicate 
that ZMC2 and ZMC3 fulfill both the $\mathrm{Zn}^{2+}$-buffering and ionophore requirements for a $\mathrm{p} 53$ reactivating $\mathrm{ZMC}$ in vitro, but 3-AP does not.

ZMC2 and ZMC3, but not 3-AP, Demonstrate Enhanced Sensitivity in p53-R175H Mutant Cells. One of the cellular properties of a ZMC is enhanced sensitivity in p53$\mathrm{R} 175 \mathrm{H}$ cells lines that is a log-fold or greater than that of p53 null or WT cell lines in cell growth- inhibition assays (manifested by lower $\mathrm{EC}_{50}$ 's) (Yu et al., 2012a, 2014). This enhanced sensitivity is due to a p53-mediated apoptotic program. We sought to evaluate ZMC2, ZMC3, and 3-AP for this property using ZMC1 as a control in human tumor cell lines that were WT, null, and p53-R175 mutant (Fig. 2). All three ZMC compounds exhibited growth inhibition at markedly lower concentrations in cells expressing mutant p53 ${ }^{\mathrm{R} 175 \mathrm{H}}$ compared with the WT or p53 null controls (Fig. 2A). The $\mathrm{EC}_{50}$ values for ZMC2 and ZMC1 were similar in treated p53-R175H mutant cells $\left(\mathrm{EC}_{50} 0.87 \mu \mathrm{M}\right)$. The $\mathrm{EC}_{50}$ of ZMC3 was approximately 6 -fold greater $\left(\mathrm{EC}_{50} 3.40 \mu \mathrm{M}\right)$ but was still preferentially toxic for the p53-R175H cell lines as the $\mathrm{EC}_{50}$ in the WT and null cell lines was not reached. In contrast, 3-AP does not exhibit increased sensitivity in $\mathrm{p} 53-\mathrm{R} 175 \mathrm{H}$ cells compared with p53-WT or p53-null cells (Table 1). To verify that the observed growth inhibition is p53-dependent, we used siRNA to TP53 to knockdown the expression of p53 and measured the cell growth in response to drug treatment. ZMC2 and ZMC3, like ZMC1, showed differential cellular sensitivity, but 3-AP did not (Fig. 2B). Finally, to more closely

A
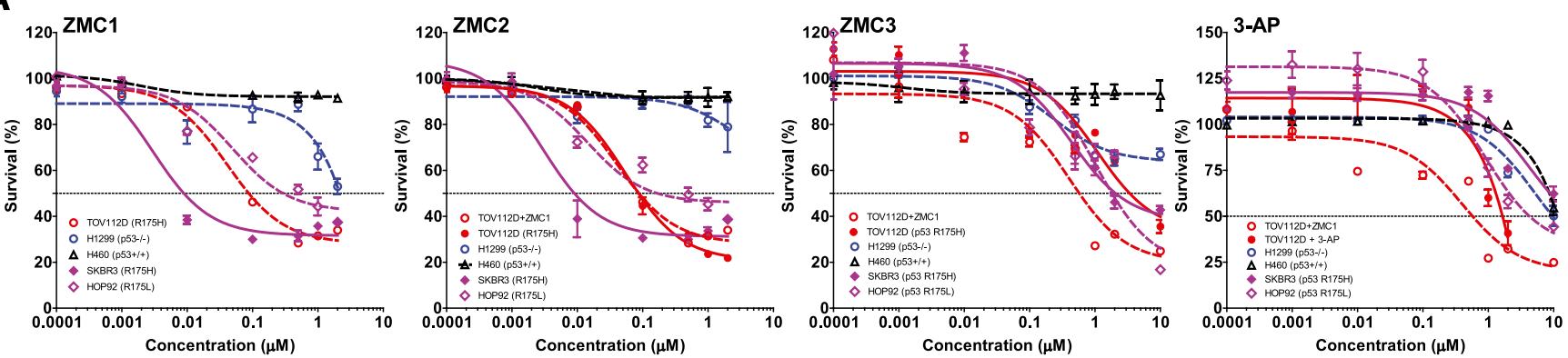

B
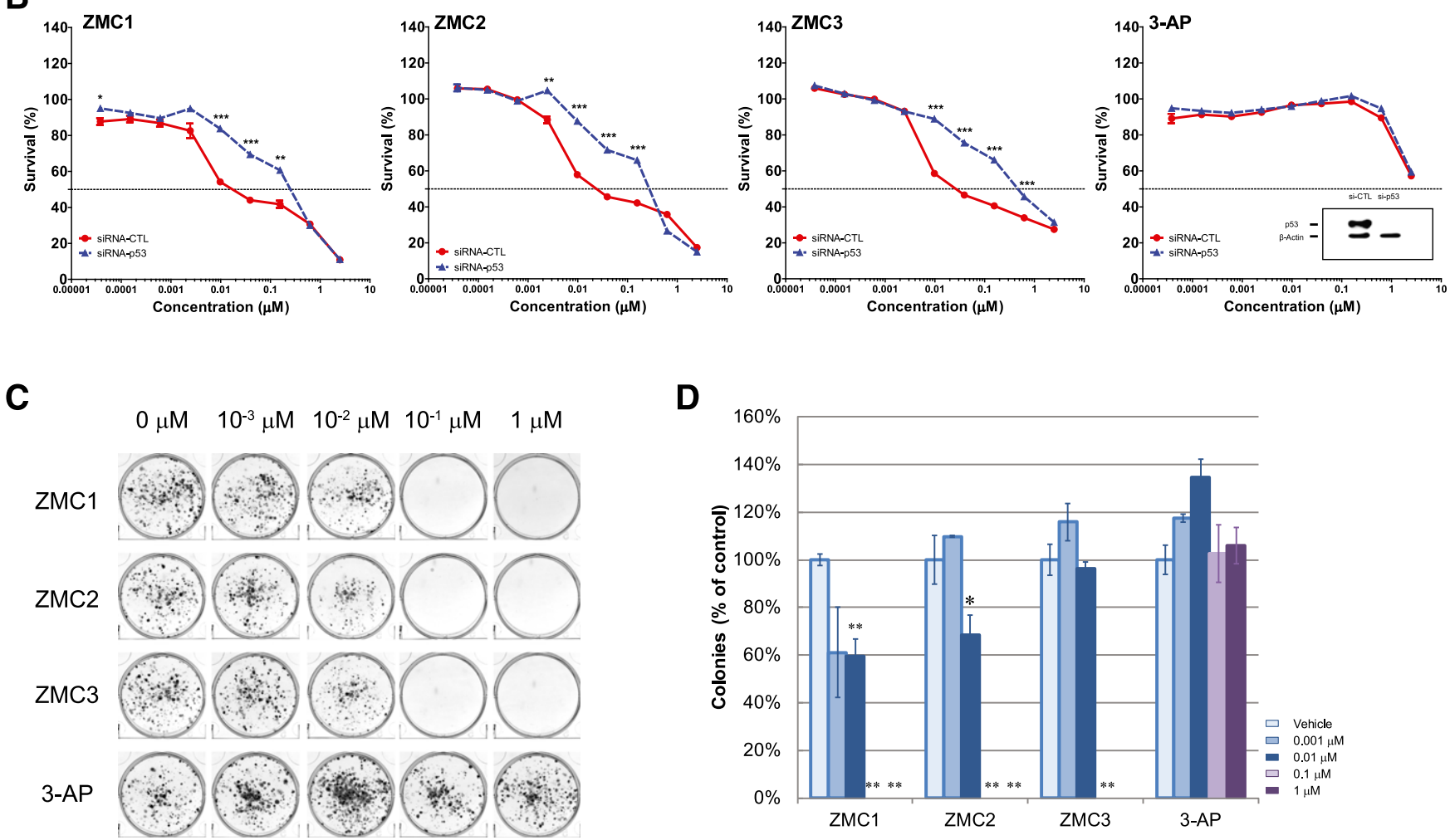

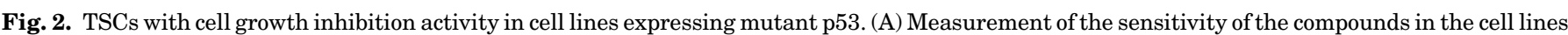

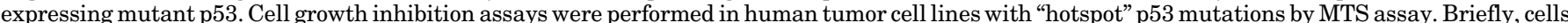

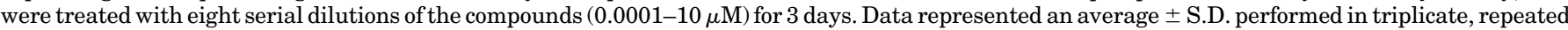

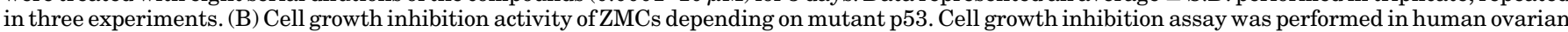

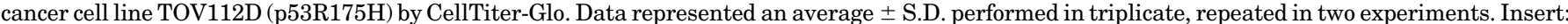

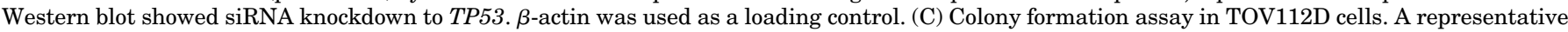

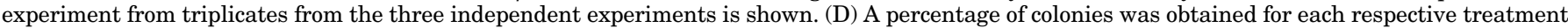
compared with that of dimethylsulfoxide (DMSO) treatment. Data are presented as mean $\pm \mathrm{S} . \mathrm{E}$. $* P<0.05 ; * * P<0.01$. 
TABLE 1

Cellular sensitivity $\left(\mathrm{EC}_{50}\right)$ to the four TSC compounds of the results shown in Fig. 2A

\begin{tabular}{lcccc}
\hline & ZMC1 & ZMC2 & ZMC3 & 3-AP \\
\hline & $\mu M$ & $\mu M$ & $\mu M$ & $\mu M$ \\
TOV112D (p53R175H) & 0.087 & 0.087 & 3.373 & 1.644 \\
SKBR3 (p53R175H) & 0.009 & 0.009 & 2.061 & $>10$ \\
HOP92 (p53R175L) & 0.291 & 0.168 & 1.807 & 4.246 \\
H1299 (p53 null) & $>2$ & $>2$ & $>10$ & 9.661 \\
H460 (p53 wt) & $>2$ & $>2$ & $>10$ & $>10$ \\
\hline
\end{tabular}

approximate mimic the conditions in a treated tumor, we sought to evaluate the effects of a 6 -hour drug treatment over a longer duration of time (compared with the 3-day drug exposure) using the colony formation assay. After 10 days, ZMC2 and ZMC3, like ZMC1, showed no growth in 0.1 and $1 \mu \mathrm{M}$ treatment, whereas 3 -AP showed a greater number of colonies than the untreated control (Fig. 2, C and D).

Induction of a "WT-Like" Conformational Change in the p53 $^{\text {R175 }}$ Mutant Cells by TSCs. Another cellular hallmark of a ZMC is the ability to induce a conformation change from mutant to WT in the p53-R175H protein (Yu et al., 2012a, 2014). Using conformation-specific antibodies and immunofluorescent staining of the $\mathrm{p} 53^{\mathrm{R} 175 \mathrm{H}}$ cells (TOV112D and SKBR3), we observed that ZMC2 and ZMC3, like ZMC1, induced a conformation change in the $\mathrm{p} 53^{\mathrm{R} 175 \mathrm{H}}$ mutant to a structure that was recognized by the WT specific antibody (PAB1620) and was no longer recognized by the mutant specific antibody (PAB240) (Fig. 3). In contrast, 3-AP failed to induce such a change.

Restoration of WT p53 Transcriptional Function by TSCs. To determine whether the conformation change observed with the $\mathrm{p} 53^{\mathrm{R} 175}$ mutant resulted in restoration of WT p53 transcriptional function, we compared the mRNA levels of two p53 targets ( $p 21$, PUMA) in the p53 ${ }^{\mathrm{R} 175 \mathrm{H}}$ cells (TOV112D and SKBR3). We found that, similar to ZMC1, ZMC2 and ZMC3 increased the levels of the p53 target genes in these cells, but no such increase was seen for 3-AP (Fig. $4 \mathrm{~A})$.

We then examined p21 protein levels at 6 and 24 hours after treatment in TOV112D and SKBR3 cells and found that ZMC2 and ZMC3 induced p21 robustly in both cell lines (Fig. 4B). 3 -AP demonstrated a weak induction of p21 in the TOV112D cells and no induction in the SKBR3 cell line. The time course of the p21 induction by 3-AP was also different. ZMCs typically induce p21 maximally by $\sim 6$ hours, followed by a fall-off approaching basal levels by 24 hours, which suggests that the p21 induction in TOV112D cells by 3-AP was more likely p53independent.

TSCs Induce Cellular ROS Levels. One of the features of TSCs is that they induce cellular ROS levels. We previously demonstrated that ZMC1 ROS induction plays an important role in the ZMC mechanism by serving as a cellular stress response that transcriptionally activates the refolded WT-like mutant protein through post-translational modifications, including phosphorylation events on serines 15 and 46 and acetylation events on lysine 120, all of which function to direct mutant p53 to induce an apoptotic program (Yu et al., 2014). To confirm that these three TSCs induce ROS in cells, we performed immunofluorescent staining on the treated cells using an antibody that detects oxidized DNA (8-oxy-dGuo) on human tumor cell lines of different p53 status. We found that all the tested compounds increased the 8-oxy-dGuo staining in both the TOV112D ( $\left.553^{\mathrm{R} 175 \mathrm{H}}\right)$ and the H1299 $\left(\mathrm{p} 53^{-/-}\right)$cells at 24 hours (Fig. 5A). Quantitatively, all four TSCs induced ROS levels from 2- to 4-fold above baseline in TOV112D cells (Fig. $5 \mathrm{~B})$.

\section{Discussion}

The TSC class of metal ion chelators has been reported to demonstrate a broad spectrum of pharmacologic activity, including antineoplastic, antiviral, antifungal, and antimalarial, all of which is due to their antiproliferative activity (Beraldo and Gambino, 2004). Their ability to chelate metal ions, such as iron, copper, and zinc, depends on an N-N-S backbone structure that functions in metal ion binding ( $\mathrm{Yu}$ et al., 2009), exemplified by the $\alpha$-pyridyl TSCs, in which the $\mathrm{N}_{\text {pyr }}, \mathrm{N}^{1}$, and $\mathrm{S}$ participate in metal ligand binding. All four compounds in this study are either $\alpha$-pyridyl TSCs or a closely related selenosemicarbazone in the case of ZMC3, in which the chalcogen donor atom is selenium. Coordination chemistry of $\alpha$-pyridyl TSCs is typically two molecules of TSC to one molecule of metal ion, combined with a proton ionization from each TSC molecule, forming a charge neutral 2:1 coordination complex with octahedral geometry. We hypothesize that the charge neutrality contributes to the observed ability of TSCmetal ion complexes to passively diffuse through cell membranes. We previously validated this concept for ZMC1 using X-ray crystallography to demonstrate that the ZMC1-zinc forms a neutral, 2:1 octahedral complex and that it functions

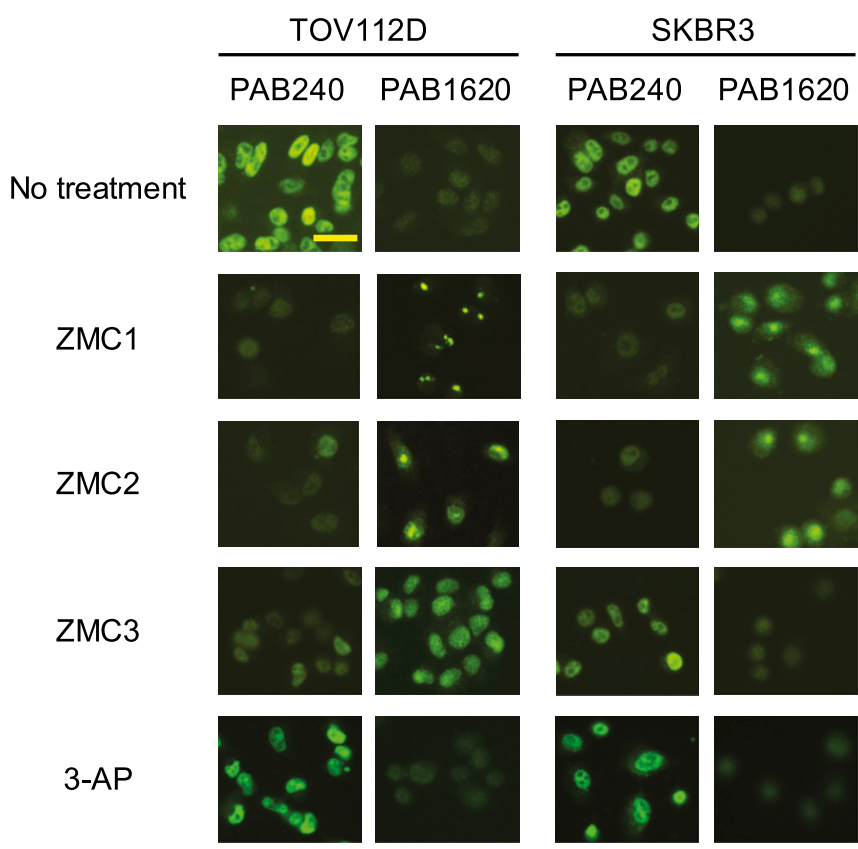

Fig. 3. A "WT-like" conformational change in the p53-175 mutant protein induced by ZMCs. Two p53 ${ }^{\mathrm{R} 175 \mathrm{H}}$ cell lines, TOV112D and SKBR3 cells, were treated with ZMC1, ZMC2, ZMC3, and 3-AP ( $1 \mu \mathrm{M}$ for 6 hours), and immunofluorescent staining was performed using p53 conformationspecific antibodies (PAB1620 for WT conformation and PAB240 for mutant conformation). Scale bar $=100 \mu \mathrm{m}$. Representative data are shown from three experiments. 

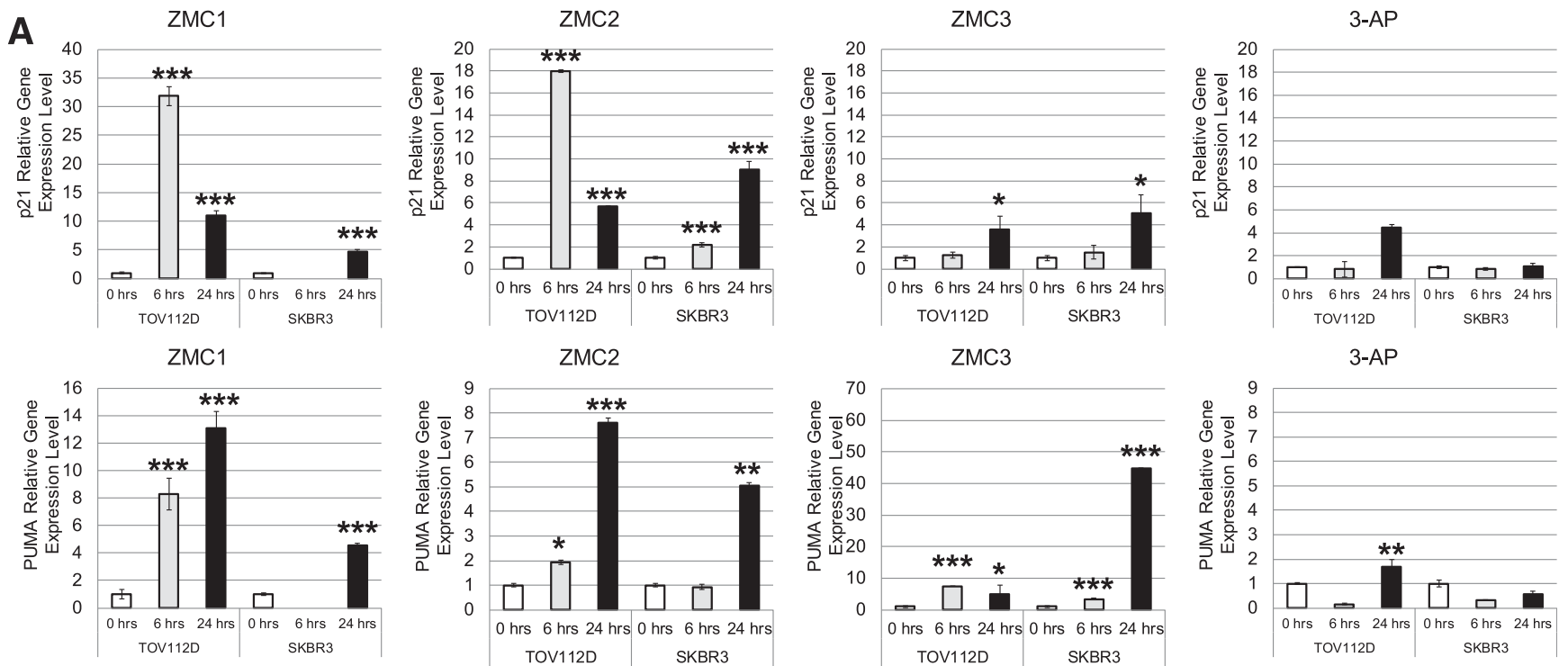

B

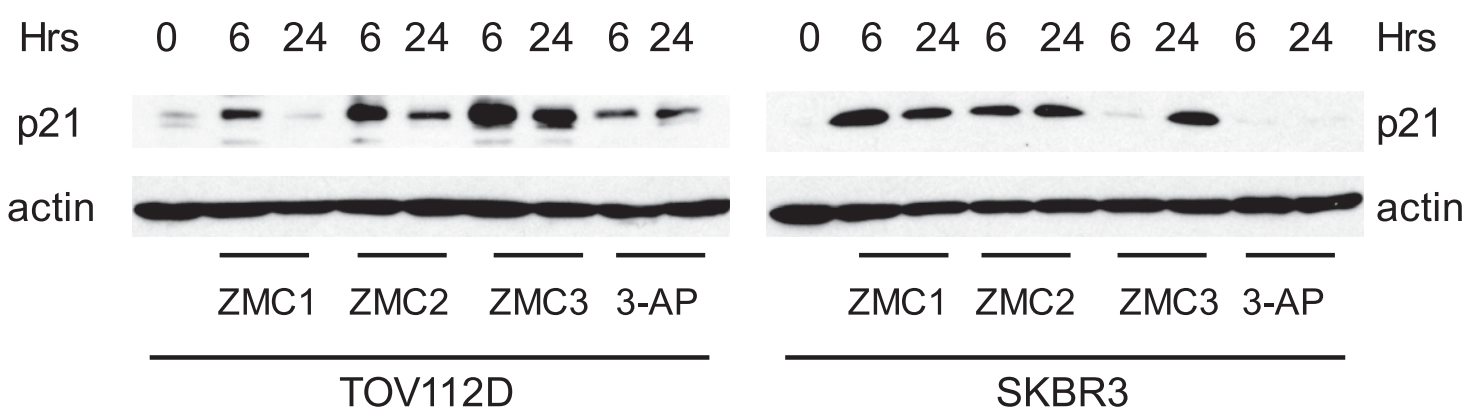

Fig. 4. Restoration of site-specific p53-175 mutant protein transactivational function by ZMC1, ZMC2, and ZMC3, but not 3-AP. (A) TOV112D and SKOV3 cells were treated with ZMC1, ZMC2, ZMC3, or 3-AP, and the gene expression of $p 21$ and PUMA was analyzed by quantitative reversetranscription polymerase chain reaction (RT-PCR). RNA was extracted from the cells using Qiagen RNeasy kit, and the gene expression level was measured by quantitative RT-PCR using TaqMan gene expression assays. $\beta$-actin was used as the internal control. Data represent an average \pm S.D. performed in triplicate, repeated in three experiments. ${ }^{*} P<0.05 ; * * P<0.01 ; * * * P<0.001$. (B) Expression of p21 in TOV112D and SKBR3 cells that were treated with ZMC1, ZMC2, ZMC3, and 3-AP were analyzed by Western blot with p21 antibody. $\beta$-actin is used as a loading control. Representative data are shown from three experiments.

as a zinc ionophore to raise intracellular zinc concentrations (Blanden et al., 2015b).

The mechanism of action of TSCs as anticancer drugs has been attributed mostly to their chelation of Fe. TSCiron complexes are redox active and thus generate hydroxyl radicals through the oxidation of $\mathrm{H}_{2} \mathrm{O}_{2}$, which increases cellular ROS (Yu et al., 2009). This activity is best exemplified by $3-\mathrm{AP}$, the only TSC that is currently in clinical trials as an anticancer drug. The mechanism of action of 3-AP has been reportedly due to its inhibition of the iron-dependent enzyme, ribonucleotide reductase (RR) (Finch et al., 1999, 2000). The inhibition of this enzyme does not seem to be due to chelation of iron from this enzyme, but rather it is due to the quenching of the labile tyrosine free radical on the $\mathrm{R} 2$ subunit via ROS generated by the TSC-iron complexes (Thelander and Graslund, 1983; Shao et al., 2006; Popović-Bijelić et al., 2011).
A

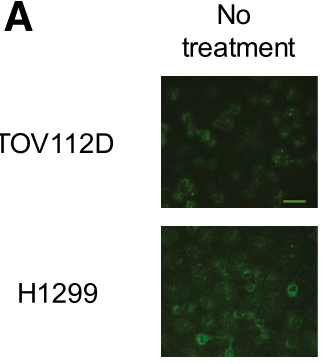
ZMC1

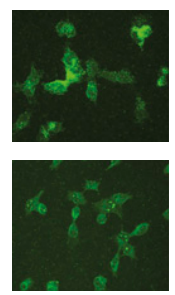

ZMC2

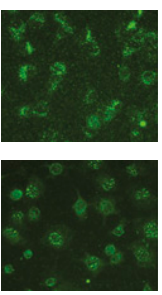

ZMC3

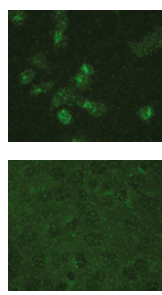

3-AP

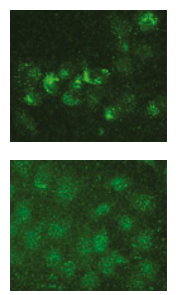

B

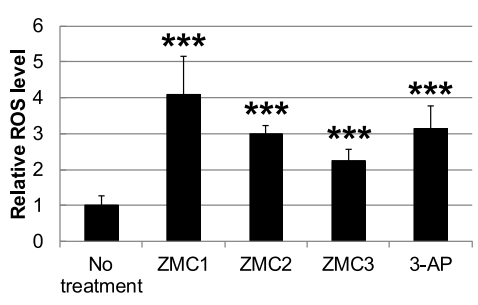

Fig. 5. ZMC1 induces ROS levels in cells as detected by 8-oxy-dGUO staining. (A) Cells were treated with ZMC1, ZMC2, ZMC3, or 3-AP and stained with 8-oxy-dG antibody. Scale bar represented a size of $100 \mu \mathrm{m}$. Representative data are shown from three experiments. (B) Quantification of staining in TOV112D cells. Representative data are shown from three experiments. $* * * P<0.001$. 
Consistent with this mechanism, ZMC1-3 all increase ROS similarly to 3-AP.

We have now elucidated another mechanism of action for TSCs as anticancer drugs, which is to function as zinc metallochaperones to reactivate mutant $\mathrm{p} 53$. The characteristics that define a ZMC have yet to be fully characterized, but at this time, zinc $K_{\mathrm{d}}$, membrane permeability, zinc ionophore activity, and the generation of ROS all seem to play an important role. The exact $K_{\mathrm{d}}$ range that defines a ZMC is unknown; however, our results showing 3-AP with a $K_{\mathrm{d}}>$ $1 \mu \mathrm{M}$, combined with our previous observations about control compound A6 $\left(K_{\mathrm{d}}=1.1 \mu \mathrm{M}\right)$, provides some clue as to the upper limit.

Given that 3-AP can generate a ROS signal yet cannot function as a ZMC, suggests that the ROS signal generated by these four TSCs studied here is related to the iron or perhaps copper binding characteristics of the drugs (and not zinc). If this is true, then designing chelators that have a greater affinity for zinc and less of an affinity for iron would be optimal for ZMC drug development. Given that the generation of ROS and inhibition of RR (both due to iron binding) are also mechanisms for toxicity, this would likely result in a compound with more "on-target" effects (reactivating mutant p53) and fewer "off-target" effects, provided the ROS generation is not reduced so low as to inhibit the ROSinduced transactivation signal required in the ZMC mechanism. That said, it is also possible that there are multiple mechanisms for ROS generation used by these compounds. Indeed, in addition to the known $\mathrm{Fe}$-dependent mechanism of 3 -AP, a recent study by the Richardson group indicates that some TSCs induce lysosomal ROS via copper-dependent fenton chemistry (Stefani et al., 2015), and we have not ruled out $\mathrm{Zn}^{2+}$ displacement of redox active metals or other mechanisms arising out of interactions with the cellular milieu. If there are multiple ROS generation mechanisms in our ZMCs, the medicinal chemistry might not be so straightforward.

We have shown that a non-TSC zinc chelator (nitriloacetic acid) can function as a ZMC, at least at very high concentrations (Yu et al., 2014). Whereas this indicates that the chemical space of metal ion chelators that can function as ZMCs could be potentially large, this work indicates that the TSC class is a useful starting point to explore for undefined ZMCs. This work also leads to the conclusion that not all TSCs are ZMCs. Understanding how to chemically modulate iron and zinc binding seems important for this purpose, and $\mathrm{ZMC1}$ and 3-AP, with their vastly different zinc-binding characteristics, can serve as useful tools to understand this.

\section{Acknowledgments}

This work was supported by the National Institutes of Health (NIH), Sidney Kimmel Foundation for Cancer, and the Breast Cancer Research Foundation and NIH.

\section{Authorship Contributions}

Participated in research design: Yu, Blanden, Kimball, Loh, Carpizo.

Conducted experiments: Yu, Blanden, Tsang, Zaman, Liu, Gilleran, Bencivenga.

Contributed to reagents or analytic tools: Yu, Blanden, Tsang, Zaman, Gilleran, Bencivenga.
Performed data analysis: Yu, Blanden, Tsang, Zaman, Loh, Carpizo.

Wrote or contributed to the writing of the manuscript: $\mathrm{Yu}$, Blanden, Kimball, Loh, Carpizo.

\section{References}

Beraldo H and Gambino D (2004) The wide pharmacological versatility of semicarbazones, thiosemicarba-zones and their metal complexes. Mini Rev Med Chem 4:31-39.

Bieging KT, Mello SS, and Attardi LD (2014) Unravelling mechanisms of p53mediated tumour suppression. Nat Rev Cancer 14:359-370.

Blanden AR, Yu X, Loh SN, Levine AJ, and Carpizo DR (2015a) Reactivating mutant p53 using small molecules as zinc metallochaperones: awakening a sleeping giant in cancer. Drug Discov Today 20:1391-1397.

Blanden AR, Yu X, Wolfe AJ, Gilleran JA, Augeri DJ, O'Dell RS, Olson EC, Kimball SD, Emge TJ, Movileanu L, et al. (2015b) Synthetic metallochaperone ZMC1 rescues mutant p53 conformation by transporting zinc into cells as an ionophore. Mol Pharmacol 87:825-831.

Bozym RA, Thompson RB, Stoddard AK, and Fierke CA (2006) Measuring picomolar intracellular exchangeable zinc in PC-12 cells using a ratiometric fluorescence biosensor. ACS Chem Biol 1:103-111.

Butler JS and Loh SN (2003) Structure, function, and aggregation of the zinc-free form of the p53 DNA binding domain. Biochemistry 42:2396-2403.

Butler JS and Loh SN (2007) Zn(2+)-dependent misfolding of the p53 DNA binding domain. Biochemistry 46:2630-2639.

Finch RA, Liu M, Grill SP, Rose WC, Loomis R, Vasquez KM, Cheng Y, and Sartorell AC (2000) Triapine (3-aminopyridine-2-carboxaldehyde- thiosemicarbazone): A potent inhibitor of ribonucleotide reductase activity with broad spectrum antitumor activity. Biochem Pharmacol 59:983-991.

Finch RA, Liu MC, Cory AH, Cory JG, and Sartorelli AC (1999) Triapine (3-aminopyridine-2-carboxaldehyde thiosemicarbazone; 3-AP): an inhibitor of ribonucleotide reductase with antineoplastic activity. Adv Enzyme Regul 39: $3-12$.

Franken NA, Rodermond HM, Stap J, Haveman J, and van Bree C (2006) Clonogenic assay of cells in vitro. Nat Protoc 1:2315-2319.

Freed-Pastor WA and Prives C (2012) Mutant p53: one name, many proteins. Genes Dev 26:1268-1286.

Hainaut P and Milner J (1993) A structural role for metal ions in the "wild-type" conformation of the tumor suppressor protein p53. Cancer Res 53:1739-1742.

Haupt Y, Maya R, Kazaz A, and Oren M (1997) Mdm2 promotes the rapid degradation of p53. Nature 387:296-299.

Kunos CA, Radivoyevitch T, Waggoner S, Debernardo R, Zanotti K, Resnick K, Fusco N, Adams R, Redline R, Faulhaber P, et al. (2013) Radiochemotherapy plus 3-aminopyridine-2-carboxaldehyde thiosemicarbazone (3-AP, NSC \#663249) in advanced-stage cervical and vaginal cancers. Gynecol Oncol 130:75-80.

Levine AJ and Oren M (2009) The first 30 years of p53: growing ever more complex. Nat Rev Cancer 9:749-758.

Lokshin M, Li Y, Gaiddon C, and Prives C (2007) p53 and p73 display common and distinct requirements for sequence specific binding to DNA. Nucleic Acids Res $\mathbf{3 5}$ : 340-352.

Ma B, Goh BC, Tan EH, Lam KC, Soo R, Leong SS, Wang LZ, Mo F, Chan AT, Zee B, et al. (2008) A multicenter phase II trial of 3-aminopyridine-2-carboxaldehyde thiosemicarbazone (3-AP, Triapine) and gemcitabine in advanced non-small-cell lung cancer with pharmacokinetic evaluation using peripheral blood mononuclear cells. Invest New Drugs 26:169-173.

Méplan C, Richard MJ, and Hainaut P (2000) Metalloregulation of the tumor suppressor protein p53: zinc mediates the renaturation of p53 after exposure to metal chelators in vitro and in intact cells. Oncogene 19:5227-5236.

Murren J, Modiano M, Clairmont C, Lambert P, Savaraj N, Doyle T, and Sznol M (2003) Phase I and pharmacokinetic study of triapine, a potent ribonucleotide reductase inhibitor, administered daily for five days in patients with advanced solid tumors. Clin Cancer Res 9(11):4092-4100.

Popović-Bijelić A, Kowol CR, Lind ME, Luo J, Himo F, Enyedy EA, Arion VB, and Gräslund A (2011) Ribonucleotide reductase inhibition by metal complexes of Triapine (3-aminopyridine-2-carboxaldehyde thiosemicarbazone) a combined experimental and theoretical study. $J$ Inorg Biochem 105: 1422-1431.

Richardson DR, Sharpe PC, Lovejoy DB, Senaratne D, Kalinowski DS, Islam M, and Bernhardt PV (2006) Dipyridyl thiosemicarbazone chelators with potent and selective antitumor activity form iron complexes with redox activity. J Med Chem 49:6510-6521.

Shao J, Zhou B, Di Bilio AJ, Zhu L, Wang T, Qi C, Shih J, and Yen Y (2006) A Ferrous-Triapine complex mediates formation of reactive oxygen species that inactivate human ribonucleotide reductase. Mol Cancer Ther 5:586-592.

Stefani C, Al-Eisawi Z, Jansson PJ, Kalinowski DS, and Richardson DR (2015) Identification of differential anti-neoplastic activity of copper bis(thiosemicarbazones) that is mediated by intracellular reactive oxygen species generation and lysosomal membrane permeabilization. J Inorg Biochem 152:20-37.

Thelander L and Gräslund A (1983) Mechanism of inhibition of mammalian ribonucleotide reductase by the iron chelate of 1 -formylisoquinoline thiosemicarbazone. Destruction of the tyrosine free radical of the enzyme in an oxygenrequiring reaction. $J$ Biol Chem 258:4063-4066.

Ventura A, Kirsch DG, McLaughlin ME, Tuveson DA, Grimm J, Lintault L, Newman J, Reczek EE, Weissleder R, and Jacks T (2007) Restoration of p53 function leads to tumour regression in vivo. Nature 445:661-665.

Xue W, Zender L, Miething C, Dickins RA, Hernando E, Krizhanovsky V, CordonCardo C, and Lowe SW (2007) Senescence and tumour clearance is triggered by p53 restoration in murine liver carcinomas. Nature 445:656-660. 
Yu X, Blanden AR, Narayanan S, Jayakumar L, Lubin D, Augeri D, Kimball SD, Loh SN, and Carpizo DR (2014) Small molecule restoration of wildtype structure and function of mutant p53 using a novel zinc-metallochaperone based mechanism. Oncotarget 5:8879-8892.

Yu X, Vazquez A, Levine AJ, and Carpizo DR (2012a) Allele-specific p53 mutant reactivation. Cancer Cell 21:614-625.

Yu Y, Gutierrez E, Kovacevic Z, Saletta F, Obeidy P, Suryo Rahmanto Y, and Richardson DR (2012b) Iron chelators for the treatment of cancer. Curr Med Chem 19:2689-2702.

Yu Y, Kalinowski DS, Kovacevic Z, Siafakas AR, Jansson PJ, Stefani C, Lovejoy DB, Sharpe PC, Bernhardt PV, and Richardson DR (2009) Thiosemicarbazones from the old to new: iron chelators that are more than just ribonucleotide reductase inhibitors. J Med Chem 52:5271-5294.
Zeidner JF, Karp JE, Blackford AL, Smith BD, Gojo I, Gore SD, Levis MJ, Carraway HE, Greer JM, Ivy SP, et al. (2014) A phase II trial of sequential ribonucleotide reductase inhibition in aggressive myeloproliferative neoplasms. Haematologica 99:672-678.

Address correspondence to: Darren R. Carpizo, Rutgers Cancer Institute of New Jersey, 195 Little Albany Street, New Brunswick, NJ 08903. E-mail: carpizdr@cinj.rutgers.edu or Stewart N. Loh, Department of Biochemistry and Molecular Biology, SUNY-Upstate Medical University, 4249 Weiskotten Hall, 766 Irving Avenue, Syracuse, NY 13210. E-mail address: lohs@upstate.edu 